\title{
A defence of the vermiform appendix
}

I $\mathrm{s}$ there a more maligned human anatomic structure than the vermiform appendix? Since Charles Darwin, schoolchildren have learned to disparage it as a useless vestige of evolution with a tendency to become diseased and as a bane to humanity. It is now an anatomic outcast, the subject of much prejudice and liable to be summarily removed from the body in incidental surgical procedures even when it is perfectly healthy to spare the patient a possible episode of appendicitis.

This "worm-like" structure's lowly status, in keeping with its namesake, may be undeserved. We can now make the case in defence of the appendix, that it should be regarded as innocent until proven guilty by actual evidence of infection and disease, and that incidental appendectomy should be avoided.

The prosecution's position is well known. A 1976 article concluded in no uncertain terms that "we have reviewed the literature regarding the function of the appendix and its role in the development of cancer, incidence of acute appendicitis, pathologic findings in incidentally removed appendices, and morbidity of incidental appendectomy. Considering all parameters we conclude that incidental appendectomy is a service to the patient and should be done except where specifically contraindicated."

A lot has changed since 1976.

It can now be argued that surgical techniques afford the appendix a useful purpose. It's surgical potential has been well documented in the field of urology where it has been used for the management of incontinence and in urinary reconstruction. ${ }^{2}$

In light of this use, incidental appendectomy is no longer so easy to justify. Justification is made still more difficult when one considers that appendectomy has established complications and that the incidence of appendicitis has been declining since World War II. ${ }^{3}$

While all this should be enough to

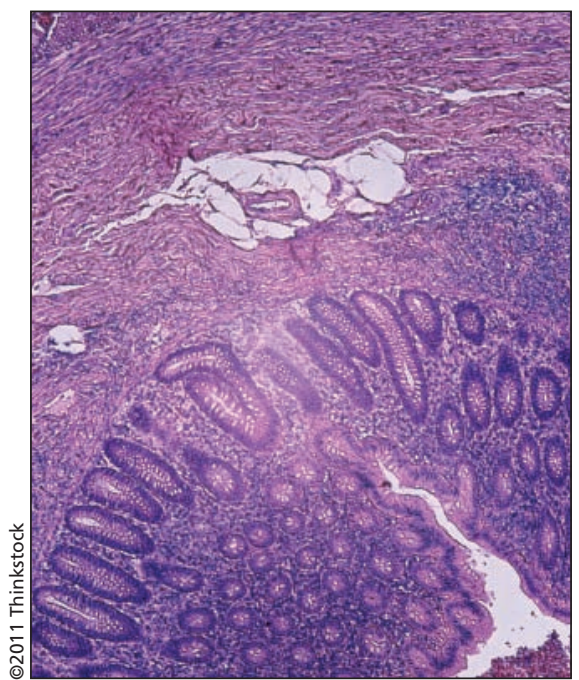

exonerate the appendix, even more evidence can be tendered in its defence. I would argue that knowledge of the biological function of the appendix has now "evolved" to the point where it appears that the appendix is, in fact, biologically useful.

Exhibit "A" for the defence is a study by researchers from Duke University ${ }^{4}$ suggesting that the appendix which is protected from infection by pathogens due to its narrow lumen and its location away from fecal flow protects and preserves beneficial bacteria. Moreover, regular shedding and regeneration of biofilms within the appendix can re-inoculate the large bowel with commensal organisms if it is flushed out in response to a pathogenic infection. An example is dysentery, still one of the leading causes of death in the developing world. Simply stated, beneficial bacteria safe-housed in the appendix can reboot the bowel. This may explain the observation that an appendectomy is a risk factor for gastrointestinal disorders such as irritable bowel syndrome.

I have no doubt that the prosecution, ever determined to put this hapless organ under the knife, will point out that this "rebooting the bowel" function will not be frequently engaged in the sterile environments of developed countries. But let's not condemn the appendix for the short-sightedness of the prosecution!

The appendix may come in handy during travels abroad or unforeseen circumstances, such as new pathogens or earthquakes, tsunamis or other disasters that may disrupt sterile environments. In these situations it is easy to imagine the vermiform appendix rising to the occasion. In addition, the advancement of surgical innovation and medical knowledge may disclose even more uses for the appendix.

In light of the foregoing, I submit that it is wise to let the healthy appendix remain for no other reason than to be an "insurance organ." Let it be there to sacrifice itself in reconstructive surgery; let it be the saviour of she who finds herself in an inhospitable environment. Just let it be.

\section{Rajbir S. Grewal BA JD LLM}

Lawyer

Department of Justice Canada

Vancouver, BC

\section{References}

1. Silvert MA, Meares EM. Rationale of incidental appendectomy. Urology 1976;7:129-34.

2. Wheeler RA, Malone PS. Use of the appendix in reconstructive surgery: A case against incidental appendecectomy. Br J Surg 1991;78:1283-5.

3. Raguveer-Saran MK, Keddie NC. The falling incidence of appendicitis. Br J Surg 1980;67:681.

4. Randal BR, Barbas AS, Bush EL, et al. Biofilms in the large bowel suggest an apparent function of the human vermiform appendix. J Theor Biol 2007; 249: 826-31.

5. Sleator RD, Cronin M, Hill C. Why appendectomies may lead to an increased risk of functional gastrointestinal disorders. Med Hypotheses 2008; 71:814-6.

The author was faced with the choice of whether to consent to an incidental appendectomy on his 20-month-old son; one surgeon recommended it, the other recommended against it.

CMAJ 2011. DOI:10.1503/cmaj.110314

Do you have an opinion about this article? Post your views at www.cmaj.ca. Potential Salon contributors are welcome to send a query to salon@cmaj.ca. 